\title{
THE EFFECT OF INDONESIAN YOUTUBER'S AND VLOGGER'S REGISTER ON YOUNG GENERATION BEHAVIOR
}

\author{
I Gede Budiasa, I Putu Weddha Savitri \\ English Department, Faculty of Arts, Udayana University \\ igedebudiasa@unud.ac.id, weddha_savitri@unud.ac.id
}

\begin{abstract}
YouTube as online platforms today has created millions of videos with varied, entertaining and useful content for millions of internet users get. This makes the content creators compete to make interesting and high quality videos. This has become a new trend among the younger generation today.

Therefore, this research is worth making to investigate the effect of the variety of Indonesian YouTuber and Vlogger on young people's language behavior. The data was collected from a number of videos uploaded by Indonesian Youtuber and Vlogger by filtering representative content. by questionnaires, interviews, and observations of youth groups to be able to hear firsthand variety of their languages. The data retrieved i on purposeful sampling method of some contents were qualitatively analyzed by applying several sociolinguistic theories. The results reveal that the variety of languages are used by well-known Youtubers and Vlogers such as Atta Halilintar, Ria Ricis, Raffi Ahmad, etc. with light and easy words such as the word gaeess, kuy, tercyduk

Youtuber's and Vlogger's style of language have an impact on the language behavior of the younger generation today in adopting their favorite language style. However this does not have a negative effect on language behavior because they are quite selective in using the Indonesian Youtuber's and Vlogger's language styles.
\end{abstract}

Keywords: register, style, Youtuber, Vlogger

\section{INTRODUCTION}

Indonesian YouTube users do not only get entertainment content but also a source of information or learning something from the content suiting the user's needs. Generally Indonesian users think that YouTube makes it easy for them to find interesting content on a variety of topics.

Increased interest in internet users for various YouTube videos brings benefits to content creators in Indonesia. Even today, Youtuber's content can be used as a land for employment and new professions because a Youtuber's income is quite high if you already have a large number of followers.

To become a Youtuber or Vlogger with a large number of subscribers, content creators are required to be more productive and creative in creating interesting, unique, and quality content in order to increase the number of observers and customers. Not only creative in terms of content, Youtubers must also have good verbal communication skills in order to convey interesting, entertaining content and easy to understand.

Based on the preliminary observations, they frequently use unique words or phrases that often produce new words, code-switching and code-mixing and slang to feel better known to customers who are mostly young people. This variety of languages is interesting to analyze because frequently, customers classified as teenagers will follow the speaking style of the YouTube and Vlogger they follow.

Based on the description above, the problem can be formulated to how the effect of the Youtubers and Vloggers on the language behavior of the younger generation today. As a sociolinguistic study, this issue is very interesting to be explored further to see the development of language use in society, especially in the younger generation. This research is also relevant to the development of teaching materials; especially for Sociolinguistics courses.

The current study aims to determine whether the young people are affected by YouTubers' and Vloggers' language variety towards their current behavior in the use of the various languages contained in their video content through YouTube.

\section{MATERIALS AND METHODS}

The data of the current study was collected by the distribution of questionnaires, interviews, and observations of youth groups in order to be to hear firsthand variety of their languages and then they were descriptively and qualitatively analyzed, to reveal the results found in this study. 


\subsection{THEORIES OF LANGUAGE VARIETY}

Language does vary as it undergoes changes along with changes in society. The change was in the form of variations in the language used according to their needs. In order that the number of variations does not reduce the function of language as an efficient means of communication, in the language arises a mechanism for selecting certain variations that are suitable for certain purposes called standard variants (Naban1984:6-7). Language variety is the language variation according to use, including the topic being discussed, the relationship of the speaker, the interlocutor, the person being discussed, and the speaker medium (Bachman, 1990). According to Felicia (2001: 8 and Trudgil,1983:100-101), languages are divided according to:

\subsubsection{THE INTRODUCTORY MEDIA OR INGREDIENTS}

\subsubsection{Variety of spoken languages}

Likewise in b as far as the mode is concerned, verbal variety is the language spoken by the language user. We can find standard verbal variations, for example when people give speeches or welcome members, in situations of lectures, and non-standard oral variations, for example in conversations between friends, in the market, or in other informal opportunities

\subsubsection{Variety of writing}

Writing variety is the language written or printed. The written variety can also be a standard or nonstandard type. The standard written variety is found in textbooks, texts, magazines, newspapers, posters, advertisements. The nonstandard variety of writing can be discovered in teen magazines, advertisements or posters.

\subsubsection{LANGUAGE VARIETY BASED ON TENOR}

The variety of languages is based on the role relationship of power and solidarity between the speakers. It differs according to whether or not the speaker is familiar: Variety of official languages, Variety of familiar languages, Variety of languages fairly formal, Variety of casual languages, and so on (see Eggins, 1994:9-10, Naban, 1984: 23, and Chaer \& Agustina, 2010: 7)

In order to figure out why language variety varieties occur the sociolinguistic aspects need referring to in the current study particularly the concept of bilingualism and its effect of bilingualism.

Sociolinguistics places language as part of social systems and communication systems and is part of certain societies and cultures. The use of language is a form of social interaction that occurs in various situations. The social interaction will be alive thanks to the activity of speaking on the language user. The speech activity will be more successful if it is supported by tools and other factors determining it, including the situation factor. Language behavior and language attitude are two things that are closely related, which can determine the choice of language and the survival of a language (Trudgill, 1983:14).

Language behavior is a person's mental attitude in choosing and using language. Basically a person is free to choose the language and also free to use that language. This freedom is a certain part of human rights. Even though someone is free to choose and use language even more in this era of globalization, we must still be aware of what was reminded by Kamaruddin (2007) that in this era of globalization we are exposed to foreign concepts and vocabulary so powerful, linguistic tools, code switching, code mixing, absorption, and transfer, but we will not simply give up on the domination of foreign cultures. All of these things should be used as a process towards disclosing the identity of the Indonesian language system. Exposure to the influence of foreign cultures and foreign languages (English) very strongly requires an increase in the ability of endurance and the development of Indonesian culture and language (see also Chaer and Agustina 2010: 151-152).

\subsection{BILINGUALISM}

This subsection is worth mentioning as the upper term for the following sociolinguistic aspects. The linguistic situation in Indonesia is indeed very complex because of a large number of languages in this beloved Indonesia. In the social life and daily activities of members of the community, in addition to Indonesian, regional languages and certain foreign languages are used in accordance with their functions, situations and language context. The linguistic situation in Indonesia is like that, if viewed from the perspective of that community or the existence of more than one language in that society, it can be called social bilingualism. 
Intensive contact between two or more languages in bilingual/multilingual situations such as in Indonesian society tends to result in the occurrence of symptoms of code switching (code-switching), code-mixing, and interference. In other words, the three symptoms are symptoms that are common as a product of bilingualism/multilingualism. In Indonesia, this phenomenon lives and thrives. Even today, emerging languages that are only used by certain groups or groups are inevitable, namely slang. All phenomena of attitude and behavior as well as variations in language such as slang provides a lot of space and opportunities for language observers, especially language researchers to be able to further explore aspects of language in sociolinguistic review (see Nababan, 1984: 27-29; Chaer and Agstina, 2010: 84).

\subsubsection{CODE SWITCHING}

Code switching occurs when the speaker uses two or more languages so that the two or more languages are used interchangeably in one message. Likewise, code switching is the event of language switching from casual variety to official variety, as well as official variety to casual variety (Chaer and Agustina, 2010: 106-107). Hymes (1974) states that code switching does not only occur between languages, but can also occur between variations or styles that exist in one language.

\subsubsection{CODE MIXING}

Mixing two languages in one sentence structure is called code mixing or the use of two or more languages or two variants of a language in a speech community with the condition that there is a main code or basic code that is used and has its function and automation; while the other codes that are involved in the speech event are only in pieces alone without its automated functions as a code (Chaer and Agustina, 2010: 107). Code mixing has the following features:

(2-1) When someone uses one word or phrase from one language

(2-2) There is no transfer of the entire clause

(2-3) There is mixing of words, phrases and clauses in a language in other languages used

\subsubsection{INTERFERENCE}

According to Kamus Besar Bahasa Indonesia, interference is the entry of an element of a language into another language which results in violation of the rules of the language in which it belongs to both violations of phonological, grammatical, lexical and semantic rules. Various causes of shifts in the use of Indonesian, not only caused by foreign languages but also by regional language interference and the influence of slang. Today foreign languages are more often used than Indonesian in almost all sectors of life. For example, Indonesians are more likely to stick to the phrase "No Smoking" rather than "Dilarang Merokok", "Stop" instead of "Berhenti", "Exit" instead of "Keluar", "Open House" for reception at home on Lebaran Day, or the community is more likely to choose "Pull" instead of "Tarik" and "Push"instead of "Dorong", and "Welcome" instead of "Selamar Datang". The use of English in public spaces has become an inevitable habit. This results in the fading of Indonesian language and culture, which slowly but surely becomes language (see Naban, 1984:35 and Chaer \& Agustina 210:120-121).

\section{RESULTS AND DISCUSSION}

The Indonesian Youtubers or Vloger style influences the language behavior of the younger generation today. The data was obtained by distributing questionnaires in Goggle form, with 100 respondents aged between 13-22 years. It is assumed that this age can be classified as the young generation (teenagers) who are the target to this study. The following is a general description of the results of the questionnaire that has been obtained.

\subsection{RESPONDENT AGE}

Of the 100 respondents who filled out the questionnaire online, $71.7 \%$ were female, and $28.3 \%$ were male. All respondents were teenagers aged 13-22 years, with the highest number of participants being aged 20 years (30\%) and 19 years $(27 \%)$. In terms of gender, respondents who answered the questionnaire consisted of $71.3 \%$ of women and $28.7 \%$ of men (see Chart 1). 


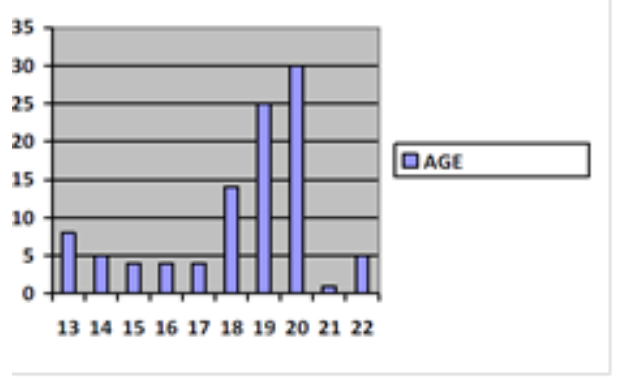

Chart 1: Respondent's Age

\subsection{FREQUENCY OF WATChING YouTUBE}

The respondents in this study are young people who are very familiar with the YouTube platform. Most of them, $41 \%$, spend more than 2 hours a day watching content on YouTube, then $34 \%$ watch YouTube less than 2 hours a day, $25 \%$ say they rarely watch YouTube. This indicates that watching videos or content on You Tube has become a daily behavior for teens today (see Chart 2).

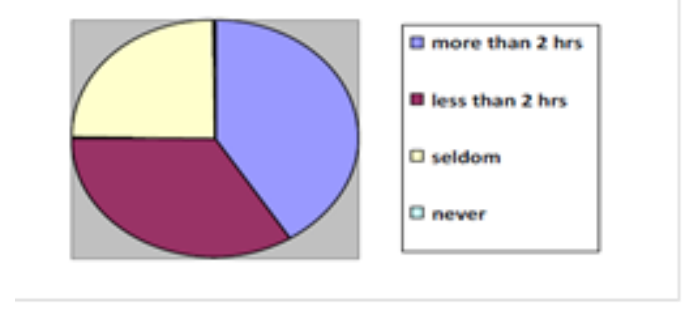

Chart 2: Frequency of Watching YouTube

\subsection{INTERESTING YOUTUBER LANGUAGE STYLE}

From the results of the questionnaire, the names of Indonesian Youtuber and Vlogger emerged, from various themes and styles that became their respective characteristics. Names like Atta Halilintar, Raditya Dika, Ria SW, Kemaz, MiauwAug, Puja Astawa, and many more, often appear as a favorite Youtuber or Vlogger. In addition to interesting content, as many as $56 \%$ of respondents agreed that if the attractive style of language is one of the factors for them to be keen on those Youtubers, $30 \%$ stated neutral, and 14\% said they disagreed if they said that the Youtubers used attractive style in the delivery of their video content and it is not the main concern why the respondents like the Youtuber or Vlogger. This can be seen in the following diagram, which is the result of the questionnaire analysis (see Chart 3 ).

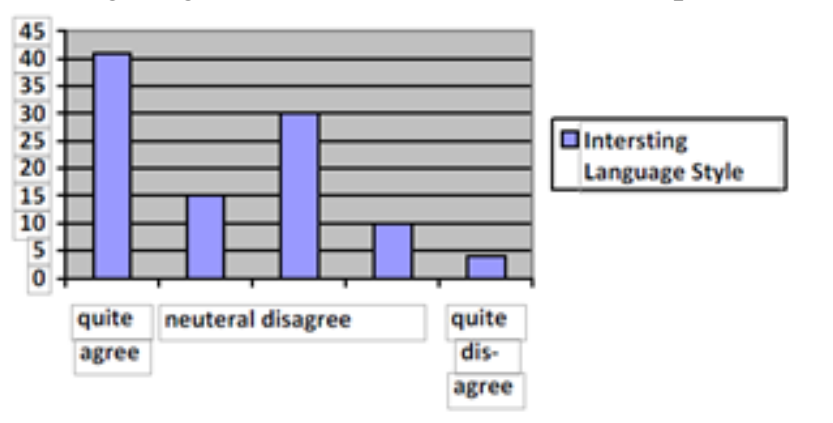

Chart 3: Interesting Youtuber Language Style

\subsection{YOUTUBE OFTEN USE SLANG AND JARGON}

As many as $44 \%$ of respondents agreed that their favorite Youtubers or Vloggers often use jargon and new words (slang) like kuy, asshiaaapp, mantul, tercyduk, receh, baper, unch, woles, bosque and others, $23 \%$ vote neutral, and 33\% said they disagreed if their favorite Youtubers and Vloggers frequently use these words. In other words, those words they often hear in video content so that they are familiar with slang words new appear, as shown by the following diagram (see Chart 4). 


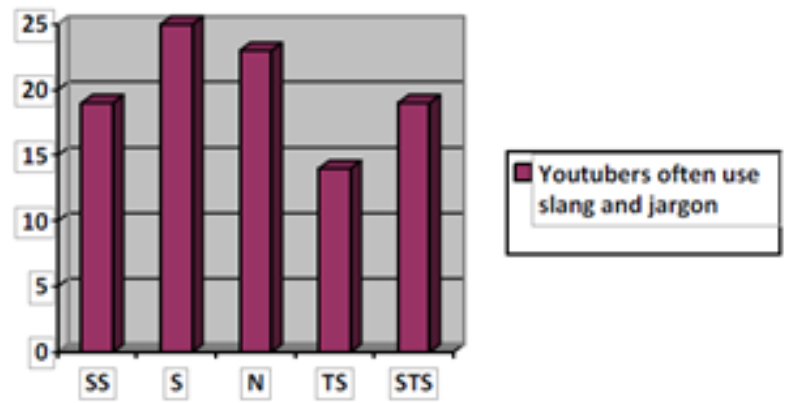

Chart 4: YouTube often use slang and jargon

\subsection{DOMAIN OF JARGON USE}

To see the effect of Indonesian Youtuber's and Vlogger's language style, the respondents are given questions in what realm they usually often use jargon of a specific Youtuber or using new words or popular slangs that is often found in video content on YouTube. The results can be seen in the following diagram (Chart 5).

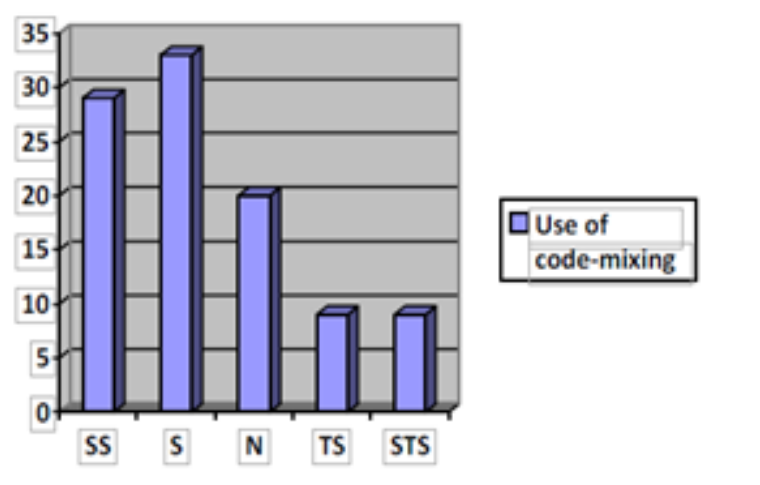

\section{Chart 5: Domain of Jargon use}

Based on the diagram above, young people often use slang words when they communicate verbally with friends $(76 \%)$, whereas in communicating in writing, they often use them on social media such as Facebook, Instagram, Twitter, and writing comment on YouTube. However, a quite interesting phenomenon seen from the results of the questionnaire is as many as $25 \%$ of respondents said they did not use the word with anyone verbally and $34 \%$ of respondents also did not use it in any media in writing. This means they are not following or being affected by the language style of the Youtubers or Vloggers in both oral and written communication even though these words are very popular. One style of language that is often used by Youtubers or Vloggers is the use of code mixing. They often slip words or phrases in foreign languages or regional languages, such as the use of the word guys which is greetings in English, where this language is now almost always in the opening sentence of the video they upload. In addition to the words guys, some words or phrases in English that are quite often tucked in the content are please, subscribe, like, let's go, welcome back to my channel, etc., even Korean is also often used by oriented Youtubers to the country of Ginseng such as anyeonghaseo, chan, This is in accordance with the polls of the younger generation in which as many as $74 \%$ of respondents said they often hear the Youtuber or Vlogger use or slip words in foreign languages or regional languages.

\subsection{USE OF CODE-MIXING}

The use of words or phrases in foreign languages or other languages that are different from the main language has become a trend and is often used in the conversation of young children, especially when chatting with friends. This behavior is supported by the results of the questionnaire which shows that $62 \%$ of respondents often insert foreign language words into daily conversation, $20 \%$ take a neutral attitude, and $18 \%$ determine the attitude of not often using or slipping foreign language words in conversation (see Chart 6). 


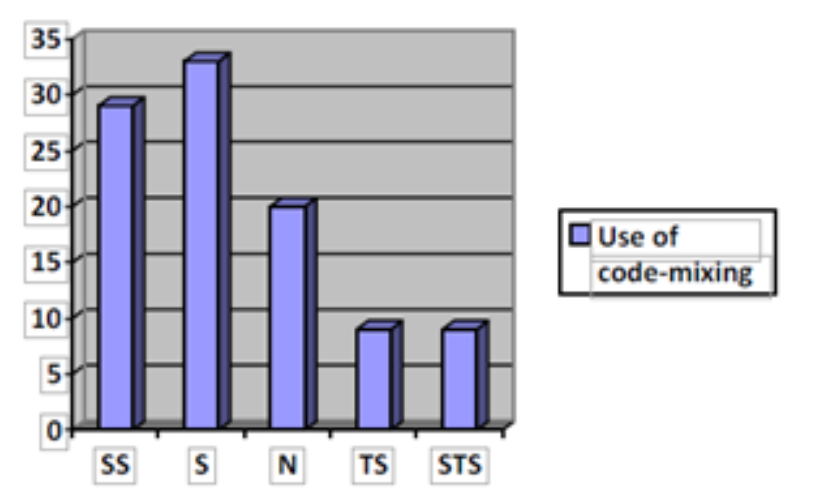

Chart 6: Use of code-mixing

\subsection{POSITIVE IMPACT ON YOUTUBE LANGUAGE STYLE}

Although the tendency to follow the popular style of YouTube or Vlogger on Youtube is quite high, $47 \%$ of respondents said they disagree whether they say that they feel more confident and look cool if they use a style of language like Youtuber, 30\% choose mediocre or neutral, and $23 \%$ agreed with the use of YouTube style to increase their confidence. They tend to use the style of language to create communication situations that are more familiar and relaxed, joking, and not monotonous. They are also quite selective in adopting the language style of the Youtubers, where they know enough not to imitate or use disrespectful words and have negative meaning (taboo). So if we conclude, the language style of Indonesian Youtubers and Vloggers does not have a significant effect on the language behavior of the young generation today. They know enough to choose and sort out what is appropriate and or inappropriate to be imitated and used in conversation. This can be seen in the following diagram as a result of the questionnaire to answer whether the style of YouTube and Vlogger has a positive effect on the development of Indonesian (see Diagram 7).

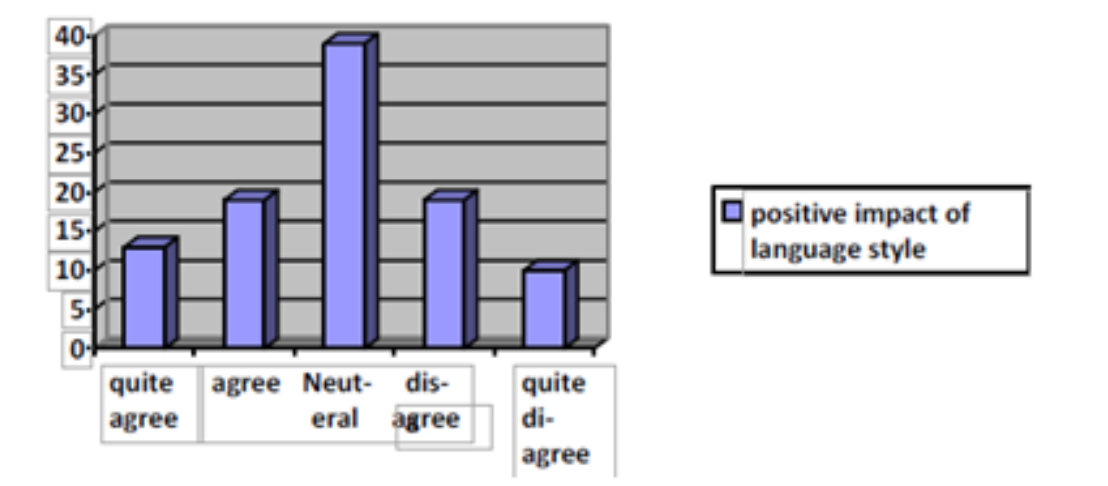

\section{Chart 7: Positive impact on YouTube language style}

Based on the diagram above, $32 \%$ of respondents choose strongly agree and agree whether the language style gives the positive influence on the development of Indonesian language, 39\% are neutral (neither positive nor negative), and $29 \%$ is expressing disapproval. Thus, it can be concluded that the style of Indonesian Youtuber and Vlogger language does not really affect the language behaviour.

\section{CONCLUSION}

Today's young generation has become a YouTube platform users who pretty much spend their time watching video content from their favorite Youtuber or Vlogger. Most of today's teens know the jargon and slang words that they often hear and see on YouTube. These words then often appear in their conversations especially when talking with friends to create a relaxed and entertaining communication atmosphere. However, they do not fully adopt the language style of the Youtubers, meaning they are quite selective by not using negative or impolite words. Therefore, not all of them agree whether the style of YouTube and Vloger have a positive effect on the development of Indonesian in general. 


\section{REFERENCES}

Cambridge University Press (2016). Meaning of "media awareness" in the English Dictionary. Retrieved from: http://dictionary.cambridge.org/dictionary/english/media-awareness

Chaer, Abdul and Agustina ,(2010). Sosiolinguistik: Perkenalan Awal. Rineka Cipta. Jakarta.

Daugherty, T., Eastin, M., \& Bright, L.f. (2008). Exploring Consumers Motivations for Creating UserGenerated Content. Journal of Interactive Advertising, 8(2).

David, Sondakh, \& Harilama. (2017). Pengaruh Konten Vlog dalam YouTube terhadap Pembentukan Sikap Mahasiswa Ilmu Komunikasi Fakultas Ilmu Sosial dan Politik Universitas Sam Ratulangi

Dredge, S. 2016. Why are YouTube stars so popular? The Guardian. Accessed on 25 January 2017. Retrieved from https://www.theguardian.com/technol-ogy/2016/feb/03/why-YouTube$\underline{\text { starspopular-zoella }}$

Eggins, Suzanne. (1994). An Introduction to Systemic Functional Linguistics. Pinter Publishers Ltd. London

Hyme, Dell. (1974). Foundation of Sociolinguisics. University of Pensylvania Press. Philadelphia.

Mironova, Ellina. (2016). Audience Behaviour and Attitude Toward Lifestyle Video Blogs on YouTube. Master Thesis, Malmo University

Nababan, P.W.J. (1984). Sosiolinguistik. P.T. Gramedia. Jakarta.

Trudgill, Peter. 1983. Sociolinguisics.: An Introduction to Language and Society. Penguin Book Ltd. England.

Variety (2014). Survey: YouTube Stars More Popular Than Mainstream Celebs Among U.S. Teens. Retrieved from http://variety.com/2014/digital/news/survey-You Tube-stars-more-popular-thanmainstream-celebs-among-u-s-teens-1201275245 
